\title{
Probabilistic Approach in Wellbore Stability Analysis during Drilling
}

\author{
Mahmood R. Al-Khayari, Adel M. Al-Ajmi, and Yahya Al-Wahaibi \\ Department of Petroleum and Chemical Engineering, Sultan Qaboos University, Muscat, Oman \\ Correspondence should be addressed to Mahmood R. Al-Khayari; mahmwood@gmail.com
}

Received 20 April 2016; Accepted 21 July 2016

Academic Editor: Alireza Bahadori

Copyright ( 2016 Mahmood R. Al-Khayari et al. This is an open access article distributed under the Creative Commons Attribution License, which permits unrestricted use, distribution, and reproduction in any medium, provided the original work is properly cited.

\begin{abstract}
In oil industry, wellbore instability is the most costly problem that a well drilling operation may encounter. One reason for wellbore failure can be related to ignoring rock mechanics effects. A solution to overcome this problem is to adopt in situ stresses in conjunction with a failure criterion to end up with a deterministic model that calculates collapse pressure. However, the uncertainty in input parameters can make this model misleading and useless. In this paper, a new probabilistic wellbore stability model is presented to predict the critical drilling fluid pressure before the onset of a wellbore collapse. The model runs Monte Carlo simulation to capture the effects of uncertainty in in situ stresses, drilling trajectories, and rock properties. The developed model was applied to different in situ stress regimes: normal faulting, strike slip, and reverse faulting. Sensitivity analysis was applied to all carried out simulations and found that well trajectories have the biggest impact factor in wellbore instability followed by rock properties. The developed model improves risk management of wellbore stability. It helps petroleum engineers and field planners to make right decisions during drilling and fields' development.
\end{abstract}

\section{Introduction}

Drilling is one of the most important and costly operations in oil industry due to the fact that if the wellbore stability cannot be accomplished, drilling will lead to higher than necessary costs. So, maintaining a stable wellbore is one of the main challenges encountered during drilling, whether a well is being drilled with overbalanced or underbalanced techniques [1].

The possible mechanical wellbore failures (rock failures) can be grouped in two main types: tensile failure and shear failure. The tensile failure represents a hydraulic fracture within the formation which normally leads to a loss in system circulation during drilling, whereas the shear failure can be simply described as the collapse of the borehole wall which may result in stuck pipe and, in severe cases, a loss of the open hole section [2]. The upper limit of the mud weight is the maximum mud weight before the onset of tensile failure (fracturing). It can be obtained by conducting a leak off test. On the other hand, the minimum allowable mud pressure is the critical pressure before a wellbore collapse.
The most common well failure during drilling is borehole collapse. The method of analyzing this case involves the use of wellbore stability modeling consisting of a constitutive model coupled with a failure criterion. The constitutive model describes the deformation properties of the rock and the failure criterion determines the limits of the deformation [3].

This paper presents a model that accounts for uncertainties of rock properties and in situ stresses as well as wellbore trajectories in order to estimate the critical mud pressure during drilling. Unlike conventional stability models that deal with static values, this probabilistic model uses Monte Carlo simulation method in order to study the impact of uncertainties on wellbore instability [4]. It was developed by utilizing a linear elastic and isotropic constitutive model in conjunction with the Mogi-Coulomb rock failure law.

Al-Ajmi and Al-Harthy [4] have developed a probabilistic borehole model to study the influence of uncertainty of input variables in vertical borehole stability. This paper discusses a probabilistic model to predict the collapse pressure for nonvertical wellbores (horizontal and deviated wells) as well as vertical wellbores during drilling. That will be done by 
applying Monte Carlo simulation to the stability model developed by Al-Ajmi and Zimmerman [5, 6].

For nonvertical wellbores, there is no closed-form analytical solution to calculate collapse pressure in order to prevent borehole instability. To solve this problem, an excel program was developed to conduct stability analysis in vertical and nonvertical boreholes and perform risk analysis in wellbore instability.

1.1. Stresses around Boreholes. A constitutive model is a set of equations needed to determine the stress state of a borehole and describe its behavior. Different models have been developed and widely studied; however, linear elastic analysis is the most common approach due to its ease of application [7] and its requirements of fewer input parameters compared with the rest of complicated models.

The stress components in cylindrical coordinates can be represented by

$$
\begin{aligned}
\sigma_{r} & =\sigma_{x^{\prime}} \cos ^{2} \theta+\sigma_{y^{\prime}} \sin ^{2} \phi+2 \sigma_{x^{\prime} y^{\prime}} \sin \theta \cos \theta, \\
\sigma_{\theta} & =\sigma_{x^{\prime}} \sin ^{2} \theta+\sigma_{y^{\prime}} \cos ^{2} \phi-2 \sigma_{x^{\prime} y^{\prime}} \sin \theta \cos \theta, \\
\sigma_{z} & =\sigma_{z^{\prime}}, \\
\sigma_{r \theta} & =\left(\sigma_{y^{\prime}}-\sigma_{x^{\prime}}\right) \sin \theta \cos \theta+\sigma_{x^{\prime} y^{\prime}}\left(\cos ^{2} \theta,-\sin ^{2} \theta\right), \\
\sigma_{r z} & =\sigma_{x^{\prime} z^{\prime}} \cos \theta+\sigma_{y^{\prime} z^{\prime}} \sin \theta, \\
\sigma_{\theta z} & =\sigma_{y^{\prime} z^{\prime}} \cos \theta-\sigma_{x^{\prime} z^{\prime}} \sin \theta,
\end{aligned}
$$

where $\sigma_{r}, \sigma_{\theta}$, and $\sigma_{z}$ are called radial, tangential, and axial stress components in a cylindrical coordinate system, respectively, while the virgin formation stresses in $(x, y, z)$ coordinate system before excavation can be expressed as

$$
\begin{aligned}
\sigma_{x}^{o} & =\left(\sigma_{H} \cos ^{2} \alpha+\sigma_{h} \sin ^{2} \alpha\right) \cos ^{2} i+\sigma_{v} \sin ^{2} \sin ^{2} i, \\
\sigma_{y}^{o} & =\sigma_{H} \sin ^{2} \alpha+\sigma_{h} \cos ^{2} \alpha, \\
\sigma_{z}^{o} & =\left(\sigma_{H} \cos ^{2} \alpha+\sigma_{h} \sin \alpha\right) \sin ^{2} i+\sigma_{v} \cos ^{2} i, \\
\sigma_{x y}^{o} & =0.5\left(\sigma_{h}-\sigma_{H}\right) \sin 2 \alpha \cos i, \\
\sigma_{y z}^{o} & =0.5\left(\sigma_{h}-\sigma_{H}\right) \sin 2 \alpha \sin i, \\
\sigma_{x z}^{o} & =0.5\left(\sigma_{H} \cos ^{2} \alpha+\sigma_{h} \sin ^{2} \alpha-\sigma_{v}\right) \sin 2 i .
\end{aligned}
$$

Equation (2) represents the virgin formation stresses which are denoted by the superscript " $o$ " on the stresses. The virgin in situ stresses will be altered by excavation. In cylindrical coordinates, the complete stress solution around an arbitrary oriented wellbore can be represented by the following:

$$
\begin{aligned}
\sigma_{r}= & \left(\frac{\sigma_{x}^{o}+\sigma_{y}^{o}}{2}\right)\left(1-\frac{a^{2}}{r^{2}}\right) \\
& +\left(\frac{\sigma_{x}^{o}+\sigma_{y}^{o}}{2}\right)\left(1+3 \frac{a^{4}}{r^{4}}-4 \frac{a^{2}}{r^{2}}\right) \cos 2 \theta \\
& +\sigma_{x y}^{o}\left(1+3 \frac{a^{4}}{r^{4}}-4 \frac{a^{2}}{r^{2}}\right) \sin 2 \theta+P_{w} \frac{a^{2}}{r^{2}},
\end{aligned}
$$

$$
\begin{aligned}
\sigma_{\theta}= & \left(\frac{\sigma_{x}^{o}+\sigma_{y}^{o}}{2}\right)\left(1+\frac{a^{2}}{r^{2}}\right) \\
& -\left(\frac{\sigma_{x}^{o}-\sigma_{y}^{o}}{2}\right)\left(1+3 \frac{a^{4}}{r^{4}}\right) \cos 2 \theta \\
& -\sigma_{x y}^{o}\left(1+3 \frac{a^{4}}{r^{4}}-4 \frac{a^{2}}{r^{2}}\right) \sin 2 \theta-P_{w} \frac{a^{2}}{r^{2}}, \\
\sigma_{z}= & \sigma_{z}^{o} \\
& -v\left[2\left(\sigma_{x}^{o}-\sigma_{o y}\right) \frac{a^{2}}{r^{2}} \cos 2 \theta+4 \sigma_{x y}^{o} \frac{a^{2}}{r^{2}} \sin 2 \theta\right], \\
\sigma_{r \theta}= & \left.-\left(\frac{\sigma_{z}^{o}-\sigma_{y}^{o}}{2}\right)\left(1-3 \frac{a^{4}}{r^{4}}+2 \frac{a^{2}}{r^{2}}\right) \sin 2 \theta\right] \\
& +\sigma_{x y}^{o}\left(1-3 \frac{a^{4}}{r^{4}}+2 \frac{a^{2}}{r^{2}}\right) \cos 2 \theta, \\
\sigma_{r z}= & \left.\sigma_{x z}^{o} \cos \theta+\sigma_{y z}^{o} \sin \theta\right)\left(1-\frac{a^{2}}{r^{2}}\right), \\
\sigma_{\theta z}= & \left.-\sigma_{x z}^{o} \sin \theta+\sigma_{y z}^{o} \cos \theta\right)\left(1+\frac{a^{2}}{r^{2}}\right),
\end{aligned}
$$

where " $a$ " is the radius of the wellbore, $P_{w}$ is the internal wellbore pressure, and $v$ is Poisson's ratio. The angle $\theta$ is measured clockwise from $x$-axis, as shown in Figure 1.

In a linear elastic material, the largest stress concentration occurs at the borehole wall. Therefore, borehole failure is expected to initiate there [8-10]. For wellbore instability analysis, consequently, stresses at the borehole wall are the ones that should be compared against a failure criterion.

Estimating the stresses at borehole wall in the case of deviated wellbore is done by setting $r=a$ in (2); the results will be as follows:

$$
\begin{aligned}
\sigma_{r} & =P_{w} \\
\sigma_{\theta} & =\sigma_{x}^{o}+\sigma_{y}^{o}-2\left(\sigma_{x}^{o}-\sigma_{y}^{o}\right) \cos 2 \theta-4 \sigma_{x y}^{o} \sin 2 \theta-P_{w}, \\
\sigma_{z} & =\sigma_{z}^{o}-v\left[2\left(\sigma_{x}^{o}-\sigma_{y}^{o}\right) \cos 2 \theta+4 \sigma_{x y}^{o} \sin 2 \theta\right], \\
\sigma_{\theta z} & =2\left(-\sigma_{x z}^{o} \sin \theta+\sigma_{y z}^{o} \cos \theta\right), \\
\sigma_{r \theta} & =0 \\
\sigma_{r z} & =0 .
\end{aligned}
$$

For vertical wellbore (Figure 2), the stresses at borehole wall are determined by setting the inclination angle $i=0$ in (2) and orienting the horizontal axes so that the direction $\theta=0$ is parallel to $\sigma H$ (i.e., $\alpha=0$ ). The stresses become

$$
\begin{aligned}
& \sigma_{r}=P_{w}, \\
& \sigma_{\theta}=\sigma_{H}+\sigma_{h}-2\left(\sigma_{H}-\sigma_{h}\right) \cos 2 \theta-P_{w}, \\
& \sigma_{z}=\sigma_{v}-2 v\left(\sigma_{H}-\sigma_{h}\right) \cos 2 \theta,
\end{aligned}
$$




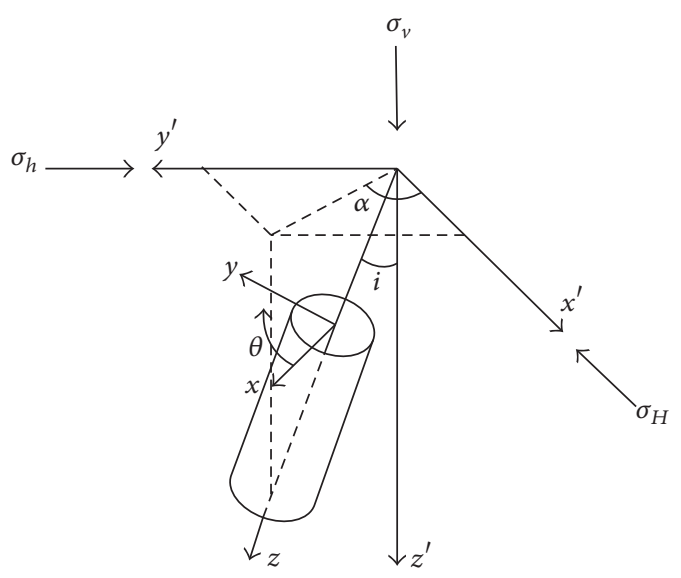

FIGURE 1: Stress transformation system for deviated borehole.

$$
\begin{aligned}
\sigma_{\theta z} & =0, \\
\sigma_{r \theta} & =0, \\
\sigma_{r z} & =0 .
\end{aligned}
$$

The stresses around a horizontal wellbore wall after excavation (Figure 3) can be represented by setting $i$ equal to $\pi / 2$ and plugging the resulted equation into (2) which gives

$$
\begin{aligned}
\sigma_{r}= & P_{w} \\
\sigma_{\theta}= & \left(\sigma_{v}+\sigma_{H} \sin ^{2} \alpha+\sigma_{h} \cos ^{2} \alpha\right) \\
& -\left(\sigma_{v}-\sigma_{H} \sin ^{2} \alpha-\sigma_{h} \cos ^{2} \alpha\right) \cos 2 \theta-P_{w} \\
\sigma_{z}= & \sigma_{H} \cos ^{2} \alpha+\sigma_{h} \sin ^{2} \alpha \\
& -2 v\left(\sigma_{v}-\sigma_{H} \sin ^{2} \alpha-\sigma_{h} \cos ^{2} \alpha\right) \cos 2 \theta \\
\sigma_{\theta z}= & \left(\sigma_{h}-\sigma_{H}\right) \sin 2 \alpha \cos \theta \\
\sigma_{r \theta}= & 0 \\
\sigma_{r z}= & 0 .
\end{aligned}
$$

In this case, where the wellbore axis lies along the maximum horizontal principal stress (i.e., $\alpha=0$ ), the stress at borehole wall is described as follows:

$$
\begin{aligned}
\sigma_{r} & =P_{w}, \\
\sigma_{\theta} & =\sigma_{v}+\sigma_{h}-2\left(\sigma_{v}-\sigma_{h}\right) \cos 2 \theta-P_{w}, \\
\sigma_{z} & =\sigma_{H}-2 v\left(\sigma_{v}-\sigma_{h}\right) \cos 2 \theta, \\
\sigma_{\theta z} & =0, \\
\sigma_{r \theta} & =0, \\
\sigma_{r z} & =0 .
\end{aligned}
$$

1.2. Rock Failure Criteria (Mogi-Coulomb Criterion). The second important element in wellbore stability is rock failure

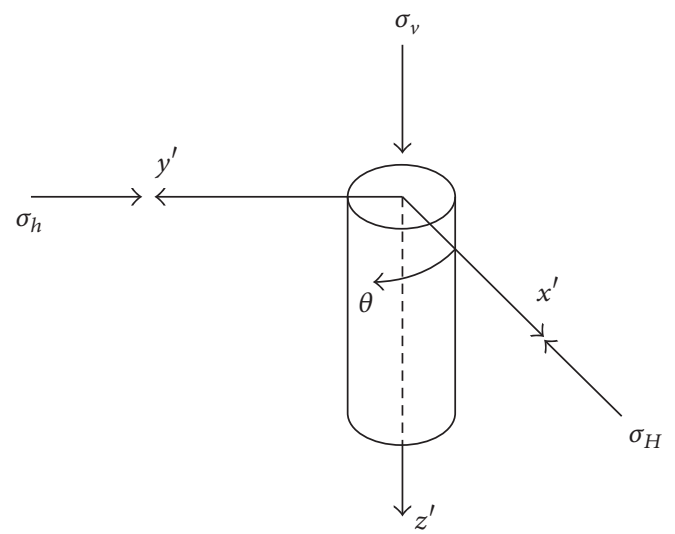

FIGURE 2: Stress transformation system for vertical borehole [12].

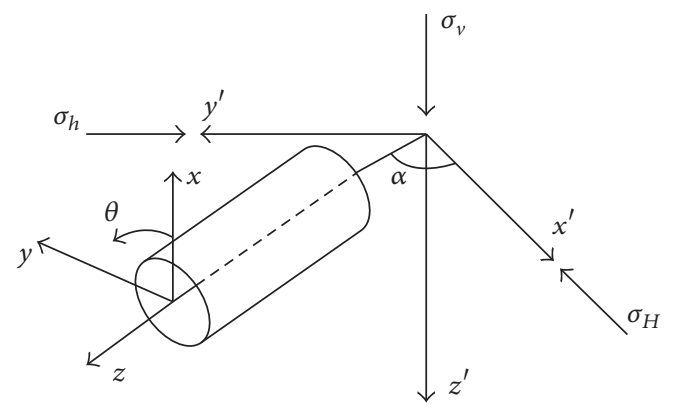

FIGURE 3: Stress transformation system for a vertical borehole.

criteria. These criteria are sets of functions in stress or strain spaces that describe or predict the condition at which rock fails under external load. In literature, many of failure criteria have been developed by scientists who suggested different approaches trying to simulate actual rock failures. In this paper, the concentration will be on Mogi-Coulomb criterion.

In 2005, Al-Ajmi and Zimmerman presented a linear form of Mogi criterion [11]. Al Ajmi found that the plotted polyaxial data of some rocks using Mogi failure envelope in $\tau_{\text {oct }}, \sigma_{m, 2}$ space can be fit to a linear model as follows:

$$
\tau_{\mathrm{oct}}=a+b \sigma_{m, 2},
$$

where $\sigma_{m, 2}$ is the effective normal stress defined by

$$
\sigma_{m, 2}=\frac{\sigma_{1}+\sigma_{3}}{2} ;
$$

$\tau_{\text {oct }}$ is the octahedral shear stress defined by

$$
\tau_{\text {oct }}=\frac{1}{3} \sqrt{\left(\sigma_{1}-\sigma_{2}\right)^{2}+\left(\sigma_{2}-\sigma_{3}\right)^{2}+\left(\sigma_{3}-\sigma_{1}\right)^{2}} .
$$

And $a$ and $b$ are the intersection of the line on $\tau_{\text {oct }}{ }^{-}$ axis and its inclination, respectively (Figure 4). Al Ajmi [12] found and verified experimentally that failure under polyaxial stresses can be predicted from triaxial test data using the linear Mogi criterion. Accordingly, he developed a new truetriaxial failure criterion called Mogi-Coulomb criterion. For triaxial stress states $\left(\sigma_{2}=\sigma_{3}\right)$ the linear Mogi criterion is exactly equivalent to Mohr-Coulomb criterion [13]. 


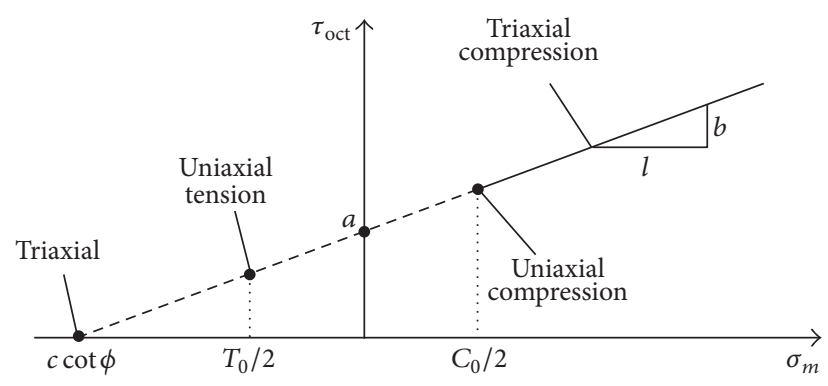

FIgURE 4: Mogi-Coulomb failure envelope [12].

Combining (8) and (9) and (7) and rearranging the equation, the failure function, $F$, will be

$$
\begin{aligned}
F= & +b\left(\frac{\sigma_{1}+\sigma_{3}}{2}\right) \\
& -\frac{1}{3} \sqrt{\left(\sigma_{1}-\sigma_{2}\right)^{2}+\left(\sigma_{2}-\sigma_{3}\right)^{2}+\left(\sigma_{3}-\sigma_{1}\right)^{2}} .
\end{aligned}
$$

Failure occurs if $F \leq 0$.

The Mogi-Coulomb parameters $(a, b)$ can be related to Coulomb failure parameters $(c, \phi)$ as follows:

$$
\begin{aligned}
& a=\frac{2 \sqrt{2}}{3} c \cos \phi, \\
& b=\frac{2 \sqrt{2}}{3} \sin \phi,
\end{aligned}
$$

where $c$ is the shear strength or cohesion of the material and $\phi$ is the internal friction angle [13].

\section{Modeling Wellbore Stability}

2.1. Vertical Wellbore Failure. To ensure mechanical wellbore stability in drilling vertical boreholes, the lower limit of the mud pressure $\left(P_{w}\right)$ must be considered to be the collapse pressure. To find the collapse pressure Kirsch solution is applied to find stresses around a borehole: radial $\left(\sigma_{r}\right)$, axial $\left(\sigma_{z}\right)$, and tangential $\left(\sigma_{\theta}\right)$. This solution then must be coupled with a failure criterion (in this research the Mogi-Coulomb criterion will be used) to end up with collapsed pressure model.

Using Kirsch solution, the stresses at the borehole wall can be defined by the following:

$$
\begin{aligned}
& \sigma_{r}=P_{w}, \\
& \sigma_{\theta}=A-P_{w}, \\
& \sigma_{z}=B .
\end{aligned}
$$

$A$ and $B$ are constants and can be defined by

$$
\begin{aligned}
& A=3 \sigma_{H}-\sigma_{h}, \\
& B=\sigma_{v}+2 v\left(\sigma_{H}-\sigma_{h}\right),
\end{aligned}
$$

where $\sigma_{v}$ is vertical in situ stress; $\sigma_{H}$ and $\sigma_{h}$ are maximum and minimum horizontal in situ stresses, respectively. And $v$ is a material constant called Poisson's ratio.

A closed-form solution for collapsed pressure can be achieved by applying (13) and (14) to the Mogi-Coulomb criterion. This solution can be used as a borehole failure model. However, in this model, there are three different permutations of the three principle stresses $\left(\sigma_{r}, \sigma_{z}\right.$, and $\left.\sigma_{\theta}\right)$ which need to be studied in order to determine the collapse pressure. These permutations are as follows: (1) $\sigma_{z} \geq \sigma_{\theta} \geq \sigma_{r}$, (2) $\sigma_{\theta} \geq \sigma_{z} \geq \sigma_{r}$, and (3) $\sigma_{\theta} \geq \sigma_{r} \geq \sigma_{z}$ (Figure 5).

Equations (15) illustrate closed-form solutions to calculate collapse pressures in vertical wellbore for in situ stress regimes, normal faulting $\left(\sigma_{z}>\sigma_{\theta}>\sigma_{r}\right)$, reverse faulting $\left(\sigma_{\theta}>\sigma_{z}>\sigma_{r}\right)$, and strike slip $\left(\sigma_{\theta}>\sigma_{r}>\sigma_{z}\right)$, respectively:

$$
\begin{aligned}
& P_{w b 1} \\
& =\frac{1}{6-2 b^{\prime 2}}\left[\left(3 A+2 b^{\prime} k\right)-\sqrt{H+12\left(K^{2}+b^{\prime} A K\right)}\right], \\
& P_{w b 2} \\
& =\frac{1}{2} A-\frac{1}{6} \sqrt{12\left[a^{\prime}+b^{\prime}\left(A-2 P_{0}\right)\right]^{2}-3(A-2 B)^{2}}, \\
& P_{w b 3} \\
& =\frac{1}{6-2 b^{\prime 2}}\left[\left(3 A+2 b^{\prime} G\right)-\sqrt{H+12\left(G^{2}+b^{\prime} A G\right)}\right] .
\end{aligned}
$$

In these equations, failure occurs if $P_{w}$ (internal wellbore pressure $) \leq P_{w b}$ (the lower limit of the mud pressure), where

$$
\begin{aligned}
& H=A^{2}\left(4 b^{\prime 2}-3\right)+\left(B^{2}-A B\right)\left(4 b^{\prime 2}-12\right), \\
& K=a^{\prime}+b^{\prime}\left(B-2 P_{0}\right) \\
& G=K+b^{\prime} A .
\end{aligned}
$$

It has been proven in literature that the most common stress distribution is the second case when $\sigma_{\theta} \geq \sigma_{z} \geq \sigma_{r}$, and it is called reverse faulting stress regime (e.g., [4-6, 8-10]).

\subsection{Probabilistic Approach Risk Analysis in Vertical Wellbore} Stability. In 2010, Al-Harthi and Al-Ajmi applied risk analysis to wellbore stability. They utilized the Mogi-Coulomb stability model (see (15), (19), and (20)) to conduct a sensitivity analysis in vertical wellbores. They carried out Monte Carlo simulation using @Risk ${ }^{\mathrm{TM}}$ program. They also conducted a sensitivity analysis using Mohr-Coulomb stability model. The comparison between the two analyses showed that the Mohr-Coulomb criterion tends to overestimate minimum overbalance mud pressure that is required to keep borehole stable during drilling (as illustrated in Figure 6). They also concluded that risk analysis is a good tool to estimate the critical mud pressure of drilling fluid with existence of uncertainties in input parameters. The sensitivity analysis of the Mogi-Coulomb criterion (which is taking in account the effect of the intermediate principal stress) showed that the maximum horizontal stress $\left(\sigma_{H}\right)$ is the most critical factor 


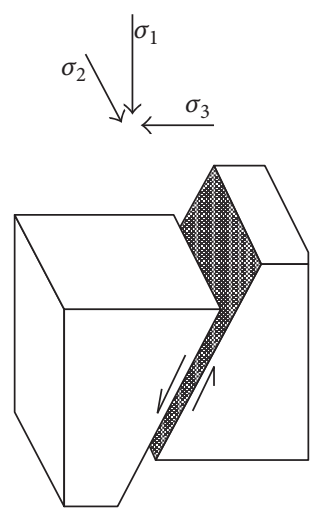

(a)

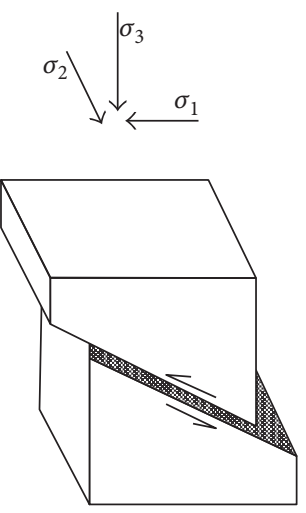

(b)
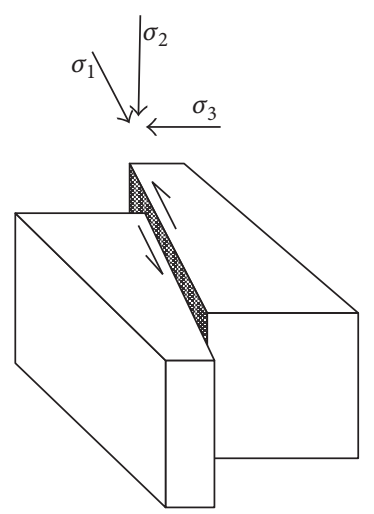

(c)

FIGURE 5: In situ stress regimes: (a) normal fault, (b) reverse fault, and (c) strike slip [12].

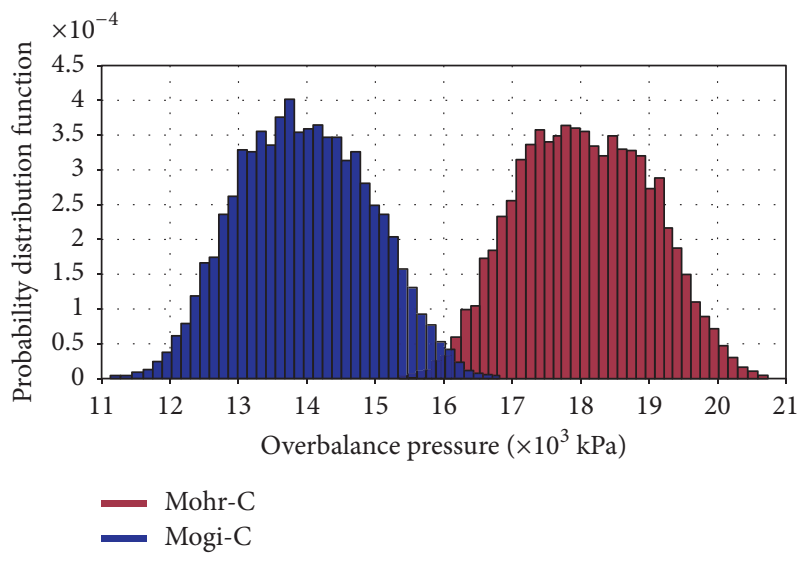

FIGURE 6: Overbalance pressure in the strike slip regime. The MogiCoulomb criterion on the left side of the graph and the MohrCoulomb criterion on the right side [4].

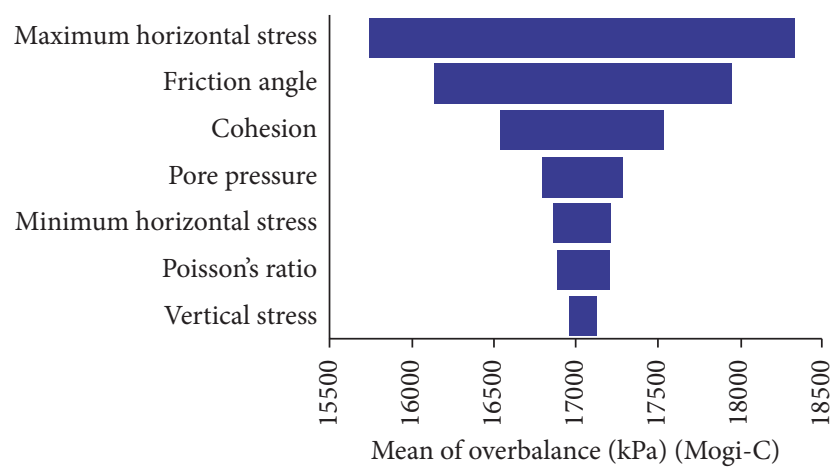

FIGURE 7: Sensitivity analysis in the strike slip regime (tornado chart for Mogi-Coulomb) [4].

in vertical wellbore stability analysis under any in situ stress regime (as illustrated in Figures 7 and 8).

2.3. Nonvertical Wellbore Failure. In order to determine the critical mud pressure (the minimum mud pressure required

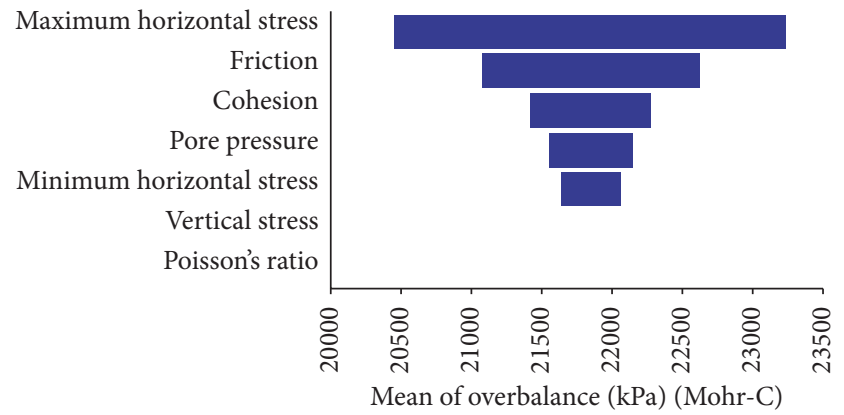

FIGURE 8: Sensitivity analysis in the strike slip regime (tornado chart for Mohr-Coulomb) [4].

to prevent borehole collapse) in deviated boreholes, the stresses at the borehole wall should be calculated using (4) and then compared with Mogi-Coulomb failure criterion. However, the resulting tangential and axial stresses are not principal stresses as the shear stress, $\sigma_{\theta z}$, may not be equal to zero. As a result, the tangential and the axial stresses should be determined using the following:

$$
\begin{aligned}
& \sigma_{1}=\frac{1}{2}\left(\sigma_{x}+\sigma_{y}\right)+\sqrt{\tau_{x y}^{2}+\frac{1}{4}\left(\sigma_{x}-\sigma_{y}\right)^{2}}, \\
& \sigma_{2}=\frac{1}{2}\left(\sigma_{x}+\sigma_{y}\right)-\sqrt{\tau_{x y}^{2}+\frac{1}{4}\left(\sigma_{x}-\sigma_{y}\right)^{2}},
\end{aligned}
$$

where $\sigma_{1}$ and $\sigma_{2}$ are tangential and axial stresses, respectively, $\sigma_{x}$ and $\sigma_{y}$ are normal stresses in $x$ and $y$ directions, respectively, and $\tau_{x y}$ is the shear stress in $x-y$ direction.

Introducing the resulting principal stresses to the MogiCoulomb failure criterion, a 4th-degree equation needs to be solved in order to find the collapse pressure. This means there is no closed-form analytical solution that can be derived for collapse pressure in deviated boreholes utilizing MogiCoulomb failure criterion similar to vertical boreholes or if Mohr-Coulomb failure criterion had been utilized [12]. 


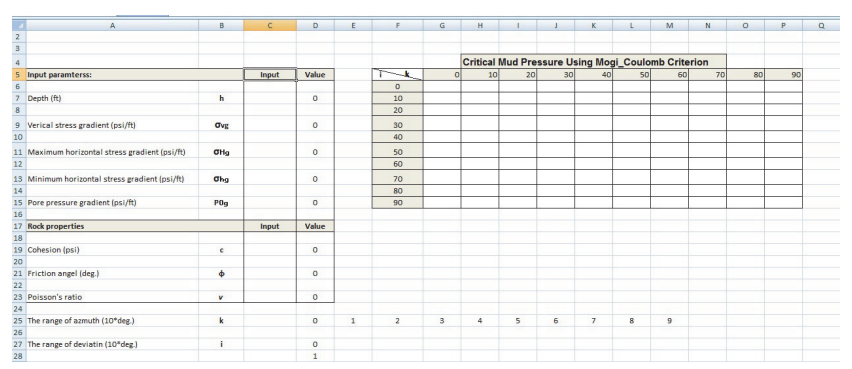

Figure 9: Interface of the deterministic instability model in Excel for nonvertical boreholes.

TABLE 1: Vertical wellbore failure for different stress regimes.

\begin{tabular}{lc}
\hline Input & Value \\
\hline$\sigma_{\mathrm{vg}}(\mathrm{psi} / \mathrm{ft})$ & 1.1 \\
$\sigma_{\mathrm{Hg}}(\mathrm{psi} / \mathrm{ft})$ & 1 \\
$\sigma_{\mathrm{hg}}(\mathrm{psi} / \mathrm{ft})$ & 0.9 \\
$P_{0}(\mathrm{psi} / \mathrm{ft})$ & 0.46 \\
Cohesion (psi) & 870 \\
Friction angle (deg.) & 31.3 \\
Poisson's ratio & 0.33 \\
\hline
\end{tabular}

\section{Probabilistic Numerical Models for Nonvertical Wellbores}

The previous section illustrates that there is no closed-form solution to model deviated wellbore stability. However, AlAjmi [12] has applied iterative loops in a computer program to calculate the collapse pressure for nonvertical boreholes. MathCAD program was used to perform these iterated loops to find the critical mud pressure (see the Appendix).

This model was utilized to build a stability model in the Excel program. In the developed model, equations of stresses and Mogi-Coulomb failure criterion have been converted from MathCAD language to the language of the Excel program. Also, the macro tool (which is using Visual Basic Programming Language) in the Excel has been utilized to do the iterated loops to calculate the collapse pressure. Figure 9 illustrates the interface of the developed model.

The input parameters of the developed model are depth $(h)$, vertical stress gradient $\left(\sigma_{\mathrm{vg}}\right)$, maximum horizontal stress gradient $\left(\sigma_{\mathrm{Hg}}\right)$, minimum horizontal stress gradient $\left(\sigma_{\mathrm{hg}}\right)$, pore pressure gradient $\left(P_{0 g}\right)$, cohesion $(c)$, friction angle $(\phi)$, and Poisson's ratio $(\mathbf{v})$.

The purpose of this model is to calculate the collapse pressure for a given set of input parameters that are constant (having static values) for 100 different well trajectory scenarios. In other words, the model will find out the collapse pressure for 10 values of inclination angle $(i)$ ranging from zero to 90 degrees multiplied by 10 values of azimuth angle (k) ranging from zero to 90 degrees too.

To ensure the validity of this model, it was run for a certain case (inputs are listed in Table 1) and compared against Al-Ajmi's MathCAD model. The output result was absolutely identical as illustrated in Figures 10 and 11.

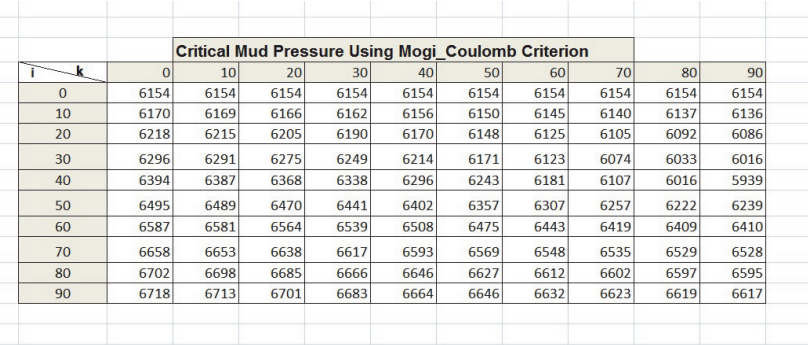

FIGURE 10: Resulting collapse pressure from the developed Excel model.

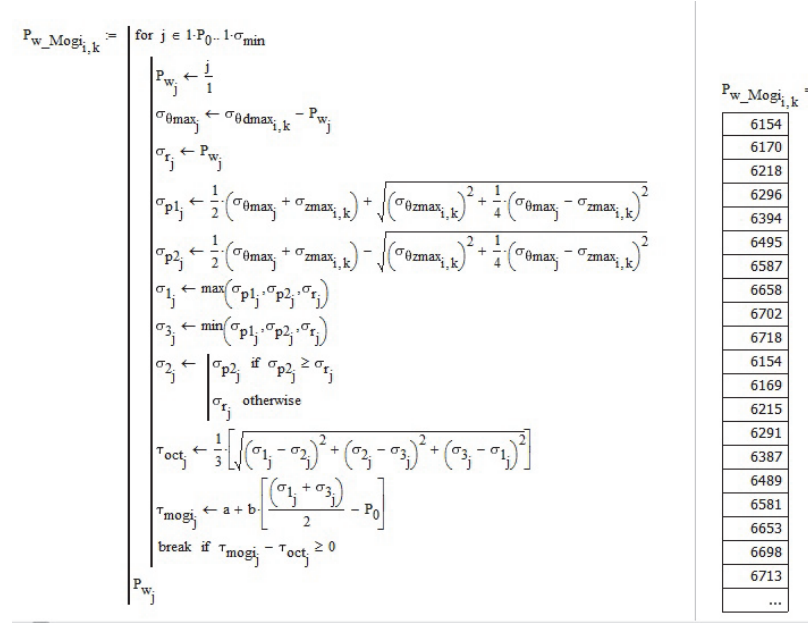

FIGURE 11: Resulting collapse pressure from the MathCAD model.

The model is consistent with Al-Ajmi's MathCAD model in calculating collapse pressure for static input parameters; however, the target is to end up with a probabilistic model in order to conduct instability risk analysis for nonvertical (deviated) wellbores. As a result, the @Risk program was utilized with the new Excel based instability model to give a probabilistic model (see Figure 12).

3.1. An Overview of @Risk Program. @Risk is an add-in program to Microsoft Excel. It is using Monte Carlo simulation that allows user to test variety of scenarios in a given model and determine the probability distribution of each outcome. When combined with a well-built model, it can give you a good feel for how likely a given outcome is for a modeled plan or business venture. In this model, the sixth version of @Risk program is used to run Monte Carlo simulation. It allows users to make decisions using the sensitivity risk analysis. In this program, parameters can be set fixed or can be given a desired range and distribution. Due to the limitation of in situ stresses and rock properties data, uniform distribution was used mostly in data simulations.

\section{Probabilistic Collapse Pressure Analysis}

The developed probabilistic wellbore collapse pressure model was run to calculate the critical mud pressure for different 


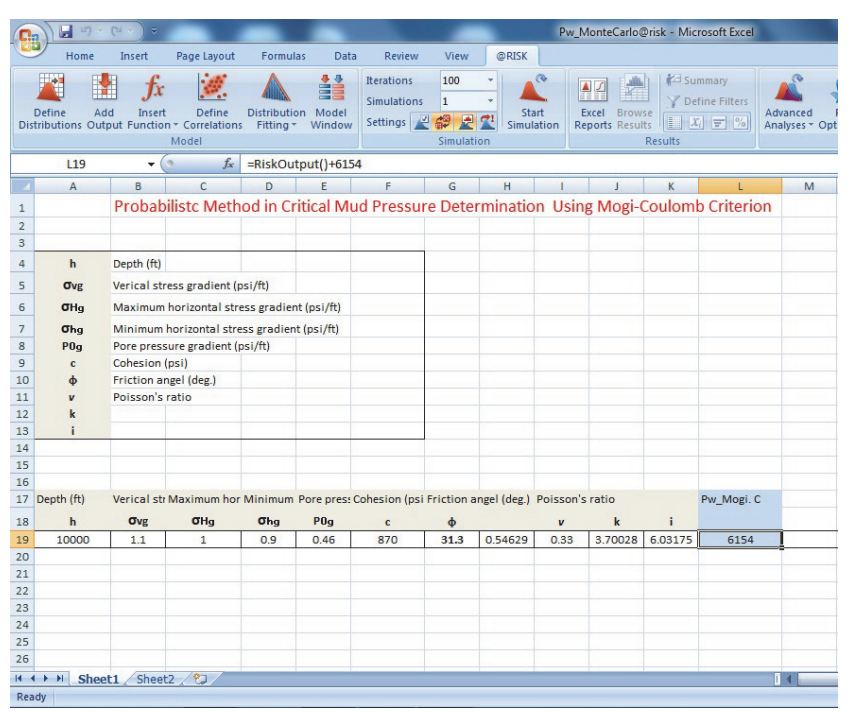

FIGURE 12: Interface of the probabilistic instability model in Excel for deviated boreholes.

cases. The model utilizes the @Risk program, and (as has been mentioned in the previous chapter) the model conducted Monte Carlo simulation for each case to capture the effect of uncertainty in input variables (in situ stresses and rock properties) in collapse mud pressure. In situ stresses and rock properties data of a sandstone formation provided in literature are used in this analysis. Uniform distribution was applied due to limitation of data. Then, for each case, a sensitivity analysis was carried out to figure out which parameter has more impact on collapse pressures.

\subsection{Collapse Pressure Risk Analysis for Normal Faulting Stress} Regime. In this case, Monte Carlo simulation was run to calculate the collapse mud pressure at normal faulting in situ stress regime. The borehole was assumed to be drilled in a sandstone formation with a depth of 3048 meters. The used field stresses condition and rock properties are described in Tables 2 and 3, respectively.

In the first simulation, all input values were given ranges of values with uniform distributions including well trajectories (inclination angle $i$ and azimuth angle $k$ ). To calculate the collapse pressures, the developed probabilistic model was run applying Monte Carlo simulation with 10000 iterations using @Risk program [14].

The histogram in Figure 13 illustrates the resulting values of possible overbalance pressures (collapse mud pressure) and their occurrence frequencies within the given ranges of input parameters. The result shows that the minimum possible value of collapse pressure is $36,780 \mathrm{kPa}$, whereas the maximum possible value is $44,790 \mathrm{kPa}$. Table 4 summarizes the statistics of the simulation.

To study the relations between input parameters and the resulting collapse pressures, scattered plots of collapse pressure versus input parameters were constructed (Figures 1416). The scattered plots of $P_{w}$ versus input parameters show that $P_{w}$ increases with deviation angle $(i)$ in a relation similar
TABLE 2: Normal faulting in situ stress regime [4].

\begin{tabular}{lcc}
\hline Field stresses $(\mathrm{kPa} / \mathrm{m})$ & Minimum & Maximum \\
\hline$\sigma_{\mathrm{vg}}$ & 21.94 & 22.62 \\
$\sigma_{\mathrm{Hg}}$ & 19.34 & 20.36 \\
$\sigma_{\mathrm{hg}}$ & 18.76 & 19.34 \\
$P_{0}$ & 10.11 & 10.52 \\
\hline
\end{tabular}

TABLE 3: Rock properties for a sandstone formation [4].

\begin{tabular}{lcc}
\hline Rock properties & Minimum & Maximum \\
\hline Cohesion $(\mathrm{kPa})$ & 4500 & 5500 \\
Friction angle (deg.) & 31 & 33 \\
Poisson's ratio & 0.2 & 0.3 \\
\hline
\end{tabular}

TABLE 4: Normal faulting Monte Carlo simulation statistics (changing all input parameters).

\begin{tabular}{lc}
\hline Statistics & $P_{w}(\mathrm{kPa})$ \\
\hline Minimum & 36,780 \\
Maximum & 44,792 \\
Mean & 40598 \\
Standard deviation & 1,687 \\
90\% confidence interval & $38,310-43,250$ \\
\hline
\end{tabular}

TABle 5: Normal faulting Monte Carlo simulation statistics (constant input parameters except $i$ ).

\begin{tabular}{lc}
\hline Statistics & $P_{w}(\mathrm{kPa})$ \\
\hline Minimum & 38,360 \\
Maximum & 40,866 \\
Mean & 39,480 \\
Standard deviation & 928.71 \\
$90 \%$ confidence interval & $38.363-40.852$ thousand \\
\hline
\end{tabular}

to (S) shape. However, there are a lot of noises associated with this relation due to the effect of other parameters. For the rest of the parameters, no well-defined relations can be figured out from plots, even though the overall trends of plotted values may give indications of general relations between $P_{w}$ and input parameters.

Another type of simulation was conducted while setting all input parameters constant except one in order to study the effect of uncertainty of unfixed parameter on the critical mud pressure. Then the simulation was repeated several times and in each time a different parameter was set variably. For the first case, deviation angle (i) was the only parameter that is given a range (from 0 to 90 degrees), whereas the rest of parameters were kept constant at the mid values of the given ranges. The occurrence frequencies of possible collapse pressures are illustrated in Figure 17. And Table 5 summarizes the statistics of the simulation. In order to study the relation between deviation angle ( $i$ ) and collapse pressure $P_{w}$, a scattered plot has been constructed. The analysis of the resulting collapse pressure shows that deviation angle (i) has an (S) shape relation with the critical mud pressure (see Figure 18). ). Figures 19 and 20 illustrate the relation of 


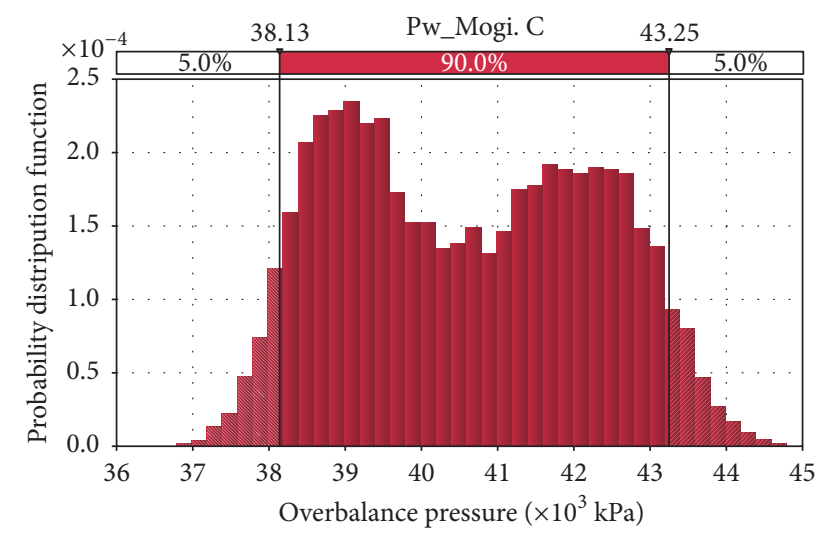

- Pw_Mogi. C

\begin{tabular}{lc}
\hline Minimum & $36,779.64$ \\
Maximum & $44,791.59$ \\
Mean & $40,598.73$ \\
Std. dev. & $1,687.01$ \\
Values & 10000 \\
\hline
\end{tabular}

FIGURE 13: Overbalance pressure in normal faulting (changing all input parameters).

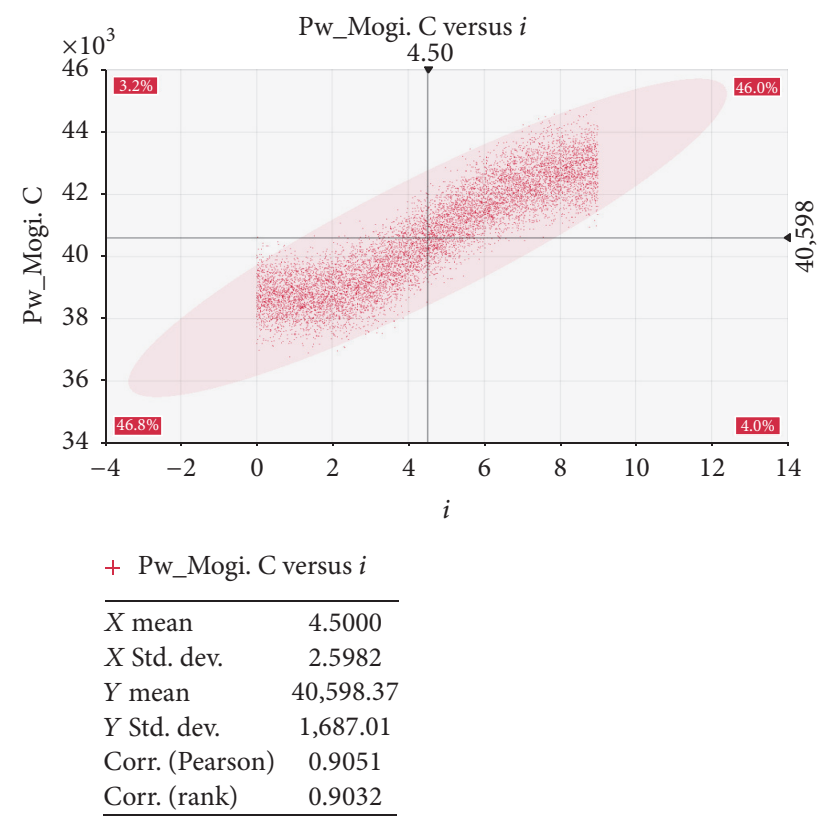

FIGURE 14: Collapse pressure ( $\mathrm{kPa}$ ) versus deviation angle (degree).

collapse pressure versus $(k)$ and collapse pressure versus $(v)$, respectively.

4.2. Sensitivity Analysis. To study the effects of uncertainty of input parameters on collapse pressures, sensitivity analysis was carried out. The constructed tornado diagram (see Figure 21) shows that deviation and azimuth angles have the most impact on the drilling fluid pressures. Friction angle and cohesion come next. This means well planner in such

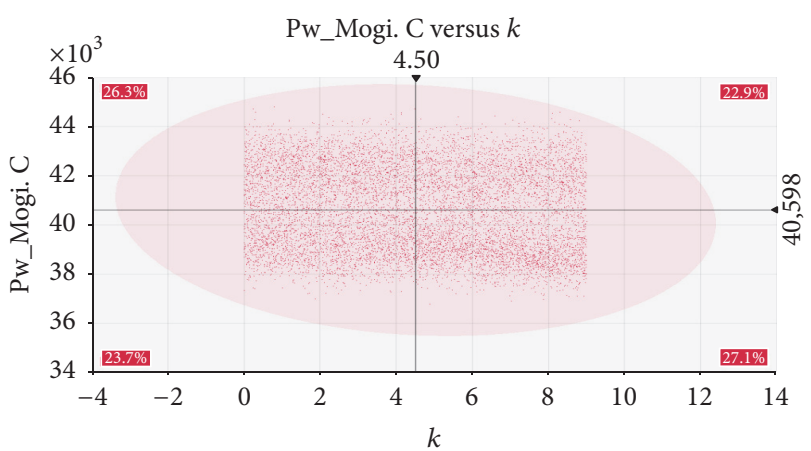

\begin{tabular}{lc}
\multicolumn{2}{l}{+ Pw_Mogi. C versus $k$} \\
\hline$X$ mean & 4.5000 \\
$X$ Std. dev. & 2.5982 \\
$Y$ mean & $40,598.37$ \\
$Y$ Std. dev. & $1,687.01$ \\
Corr. (Pearson) & -0.1068 \\
Corr. (rank) & -0.1104 \\
\hline
\end{tabular}

FIGURE 15: Collapse pressure (kPa) versus azimuth angle (degree).

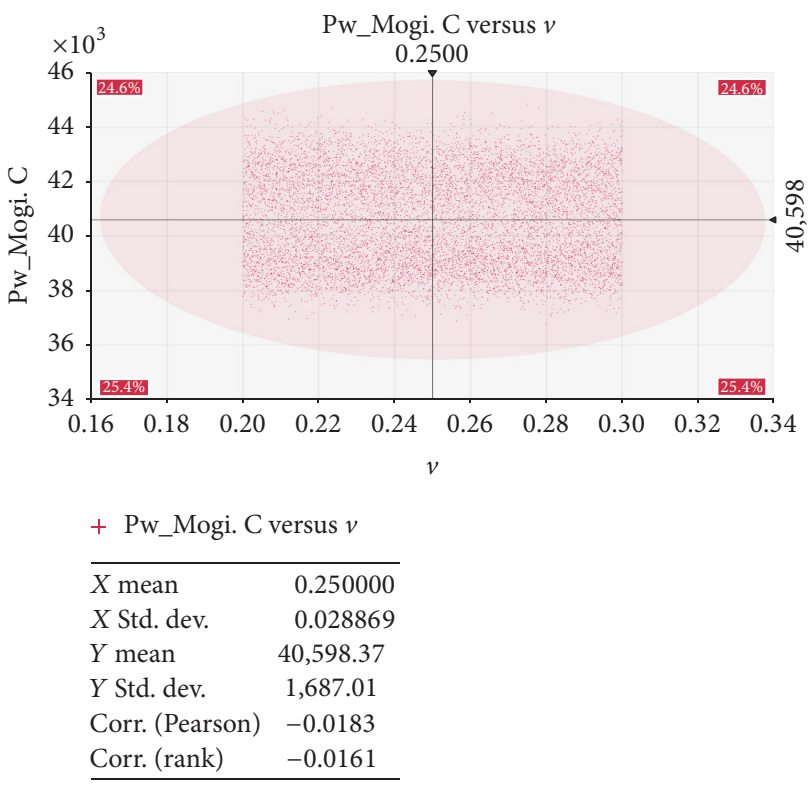

FIgURE 16: Collapse pressure $(\mathrm{kPa})$ versus Poisson's ratio.

situation should pay more attention to well trajectories and rock properties.

Similar simulations and sensitivity have been conducted for strike slip and reverse faulting stress regimes. Figures 22 and 23 illustrate the result of sensitivity analysis of input parameters on both cases, respectively.

4.3. Collapse Pressure Risk Analysis in Terms of In Situ Stresses, Rock Properties, and Well Trajectories. In this case, the target was to study the effects of uncertainty of in situ stresses, rock properties, and well trajectories as groups in borehole stability applying the developed instability model based on Mogi-Coulomb criterion. 


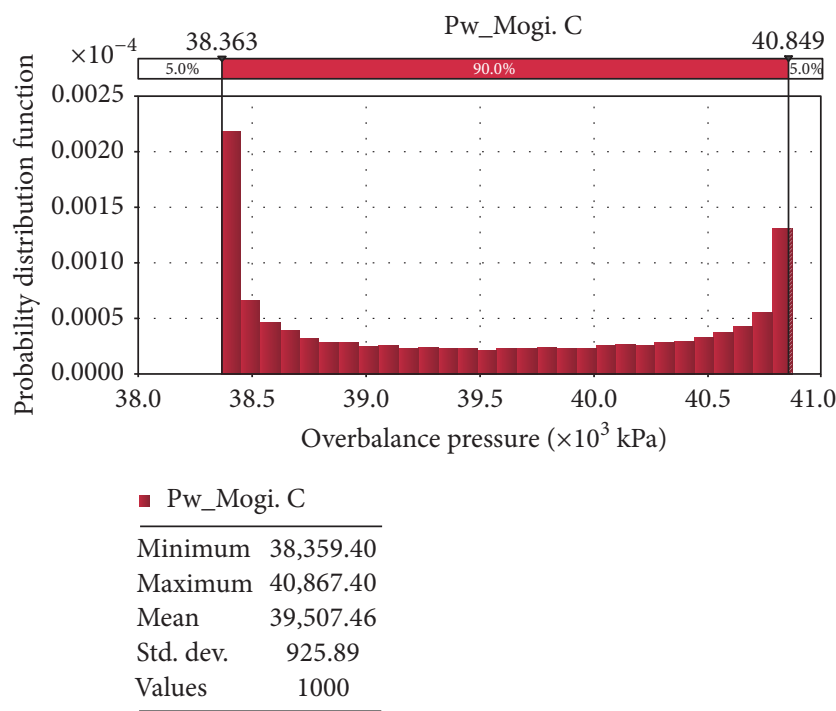

FIGURE 17: Overbalance pressure in normal faulting (constant input parameters except $i$ ).

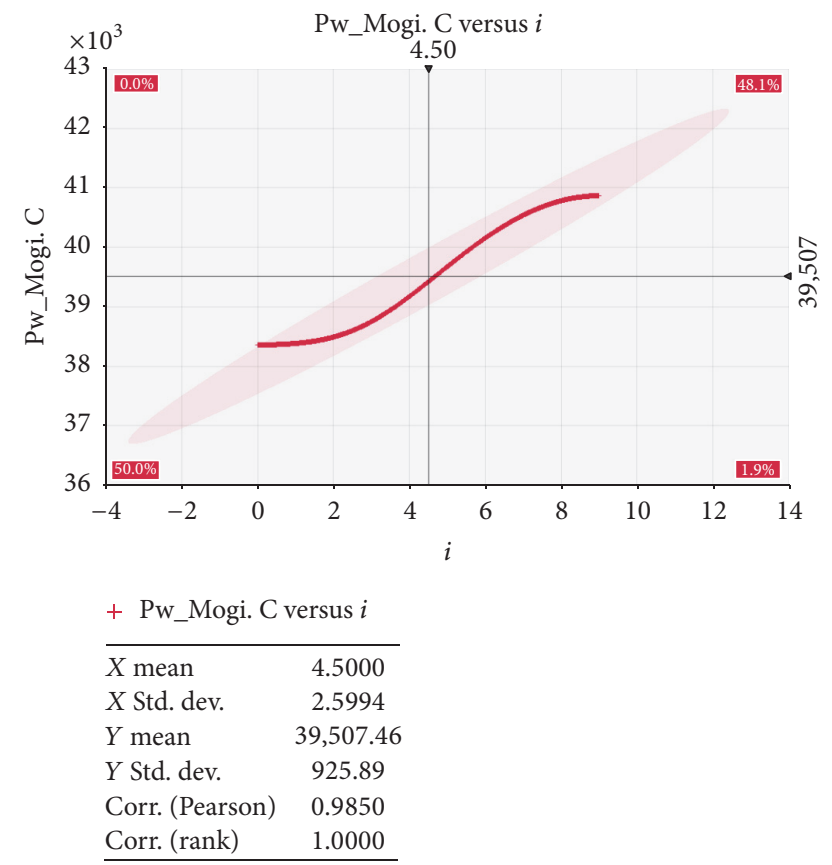

FIGURE 18: Collapse pressure (kPa) versus deviation angle (degree).

First, the model was run keeping rock properties and well trajectories at static values, while in situ stresses were given ranges of values (see Figure 24). After that, the simulation was run, while rock properties were given ranges of values, and the rest were fixed, again keeping only well trajectories variables.

Sensitivity analysis was carried out to find out which of the three groups (in situ stresses, rock properties, or well trajectories) has more effects on collapse pressure under existence of uncertainty. The tornado chart in Figure 25 shows that well trajectories group has the most impact on collapse

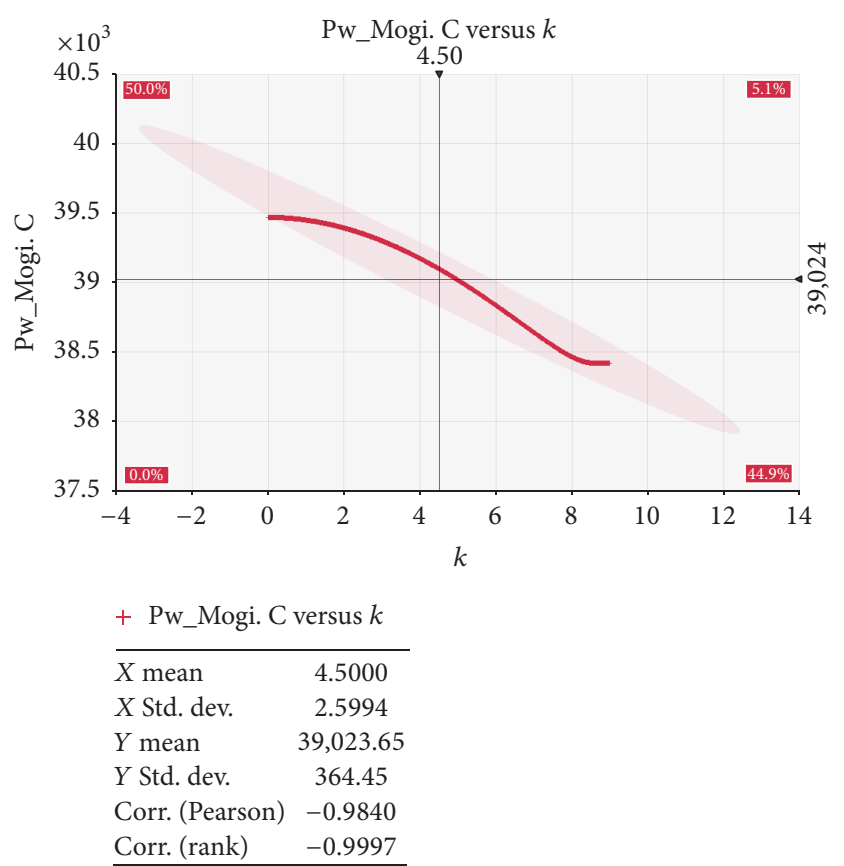

FIGURE 19: Collapse pressure ( $\mathrm{kPa}$ ) versus azimuth angle (degree).

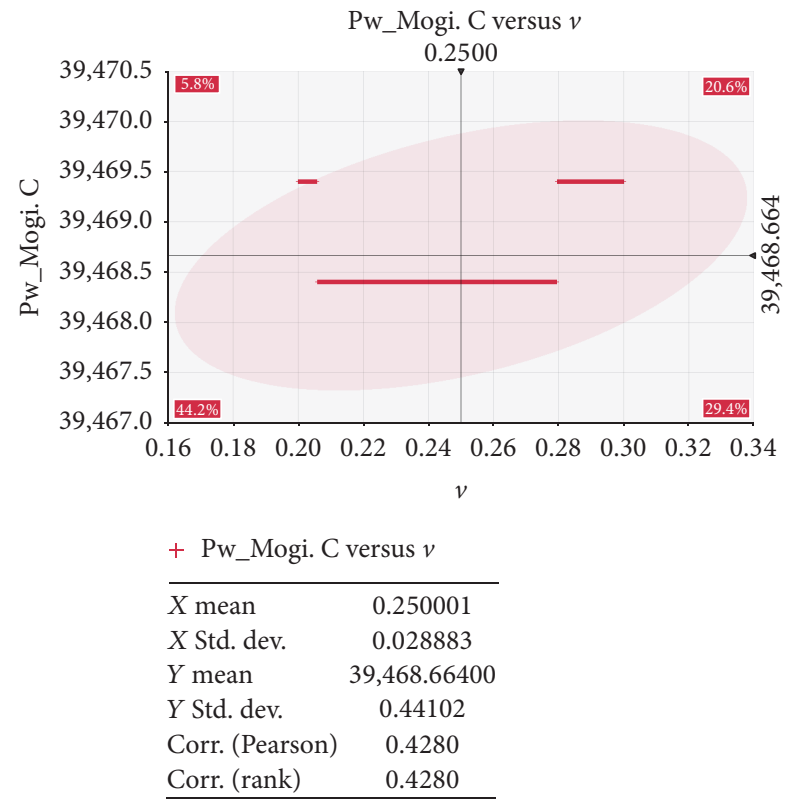

Figure 20: Collapse pressure $(\mathrm{kPa})$ versus Poisson's ratio $(v)$.

pressure. Rock properties group come next and then in situ stresses group.

\section{Conclusions}

(1) A new probabilistic model has been developed for wellbore stability analysis.

(2) The developed model has been applied in normal faulting stress regime and in strike slip stress regime 


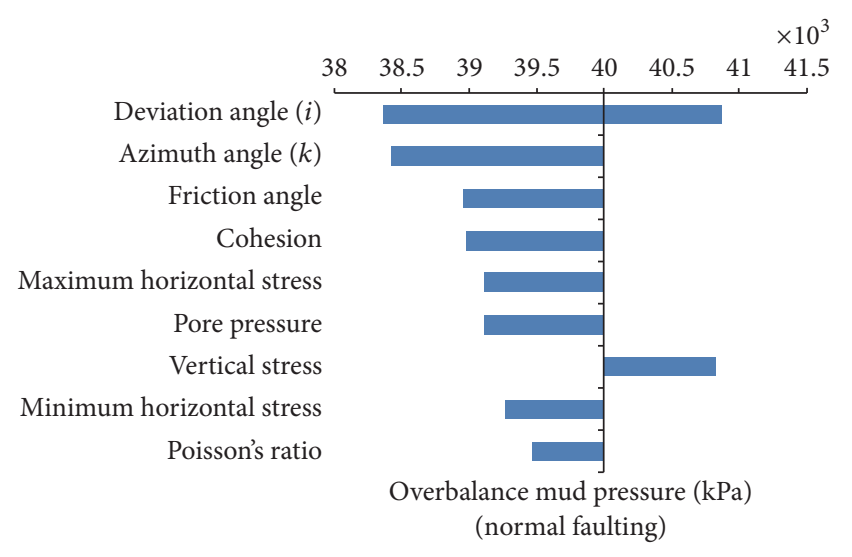

FIGURE 21: Sensitivity analysis in normal fault stress regime (tornado diagram).

Deviation angle $(i)$
Azimuth angle $(k)$
Friction angle
Cohesion
Pore pressure
$\begin{aligned} & 38 \\ & \text { Orizontal stress }\end{aligned}$
Ooisson's ratio
Vertical stress
Overbalance mud pressure (kPa) (strike slip)

FIGURE 22: Sensitivity analysis in strike slip stress regime (tornado diagram).

and reverse faulting stress regimes which are the most commonly encountered stress regimes in the field. The results indicated that the biggest impact factor in wellbore stability is the well trajectories followed by the rock strength parameters.

(3) Rock strength parameters are not precisely estimated in many field cases, while they have a significant impact in wellbore stability analysis.

(4) The critical mud pressure values in strike slip stress regime are higher than those estimated in normal faulting and reverse faulting stress regimes. That means the instability for a wellbore is high under strike slip stress regime compared to normal faulting and reverse faulting stress regimes.

(5) The influence of the formation pressure, maximum horizontal stress, and vertical stress on critical mud pressure determination is the same under normal fault and strike slip stress regimes.

(6) The increase in deviation angle in normal faulting will result in more stability. However, in strike slip regime, the higher the angle of drilling direction the less stability.

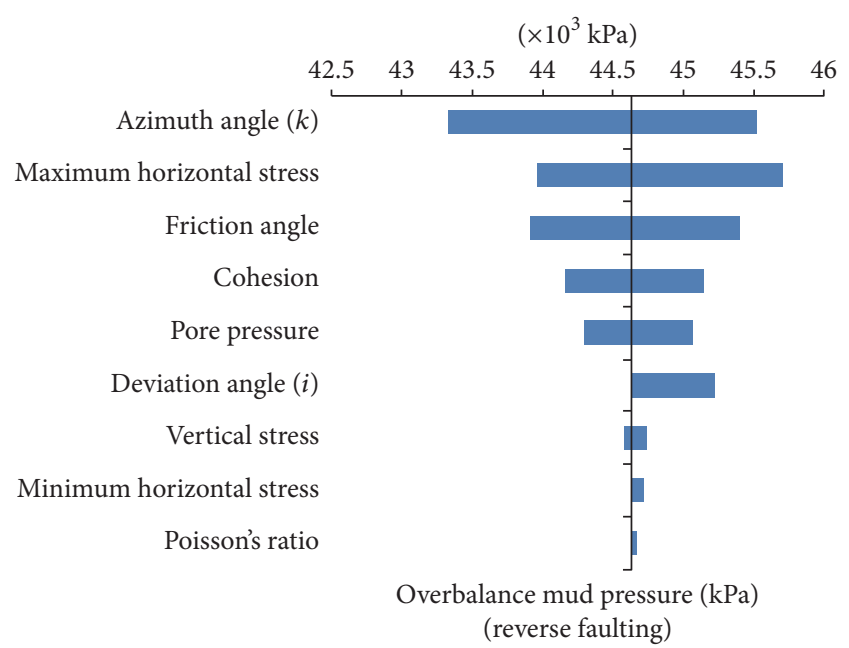

FIGURE 23: Sensitivity analysis in strike slip stress regime (tornado diagram).

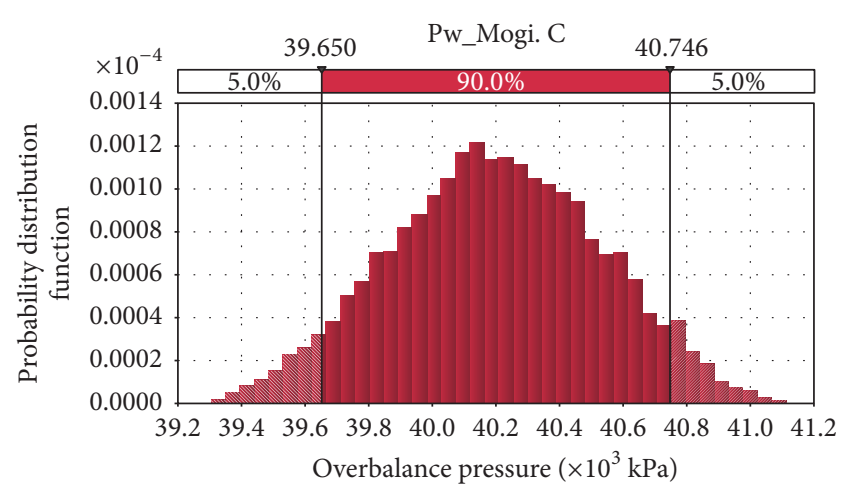

\begin{tabular}{lc} 
- Pw_Mogi. C \\
\hline Minimum & $39,303.26$ \\
Maximum & $41,113.59$ \\
Mean & $40,200.69$ \\
Std. dev. & 327.00 \\
Values & 10000 \\
\hline
\end{tabular}

FIGURE 24: Overbalance pressure (with variable in situ stresses).

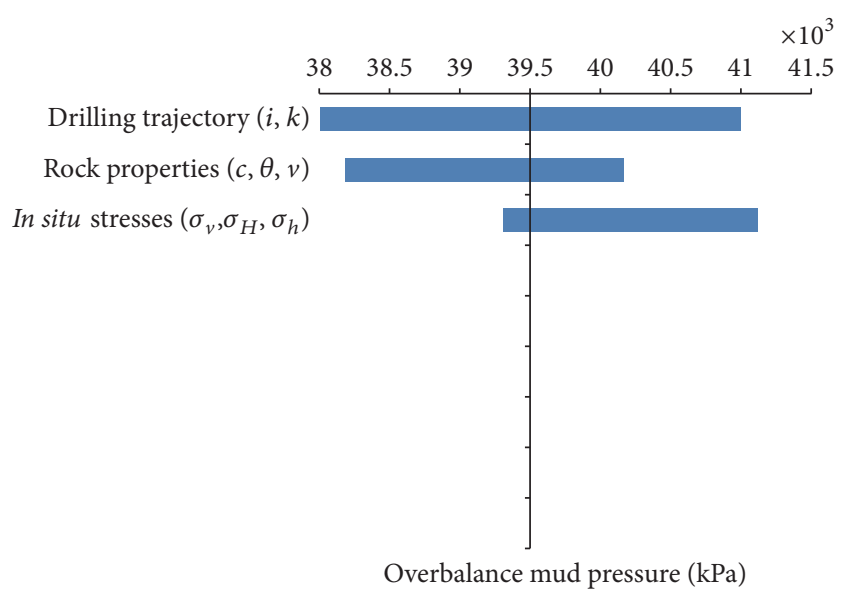

FIGURE 25: Sensitivity analysis (tornado diagram). 
(7) Normal distribution gives narrower ranges of collapse pressure than uniform distribution (higher minimum values and lower maximum values).

\section{Appendix}

\section{MathCAD Program to Calculate Collapse Pressure for Any Inclination [12]}

Input Parameters. Depth ( $\mathrm{ft}$ ) is given as follows:

$$
h:=10000 \text {. }
$$

Vertical stress gradient (psi/ft) is given as follows:

$$
\sigma_{\mathrm{vg}}:=0.95 .
$$

Maximum horizontal stress gradient ( $\mathrm{psi} / \mathrm{ft}$ ) is given as follows:

$$
\sigma_{\mathrm{Hg}}:=0.9 .
$$

Minimum horizontal stress gradient (psi/ft) is given as follows:

$$
\sigma_{\mathrm{hg}}:=0.75 .
$$

Pore pressure gradient (psi/ft) is given as follows:

$$
P_{0 g}:=0.45 \text {. }
$$

Rock Properties. Cohesion (psi) is given as follows:

$$
c:=640 \text {. }
$$

Friction angle (deg.) is given as follows:

$$
\phi:=35.2 \cdot\left(\frac{\pi}{180}\right) .
$$

Poisson's ratio is given as follows:

$$
v:=0.3 \text {. }
$$

Borehole Orientation. The range of azimuth (10x deg.) is given as follows:

$$
k:=0 \cdots 9 .
$$

The range of deviation (10x deg.) is given as follows:

$$
i:=0 \cdots 9 \text {. }
$$

Calculation of In Situ Stresses and Pore Pressure at the Depth of Interest. Vertical stress is given as follows:

$$
\sigma_{v}:=\sigma_{\mathrm{vg}} \cdot h
$$

Maximum horizontal stress is given as follows:

$$
\sigma_{H}:=\sigma_{\mathrm{Hg}} \cdot h .
$$

Minimum horizontal stress is given as follows:

$$
\sigma_{h}:=\sigma_{\mathrm{hg}} \cdot h
$$

Minimum in situ stress is given as follows:

$$
\sigma_{\min }:=\min \left(\sigma_{v}, \sigma_{H}, \sigma_{h}\right)
$$

Pore pressure is given as follows:

$$
P_{0}:=P_{0 g} \cdot h
$$

Determination of Mogi-Coulomb Strength Parameters. One has

$$
\begin{aligned}
& a:=\left(\frac{2 \cdot \sqrt{2}}{3}\right) \cdot c \cdot \cos (\phi), \\
& b:=\left(\frac{2 \cdot \sqrt{2}}{3}\right) \cdot \sin (\phi) .
\end{aligned}
$$

Estimation of In Situ Stresses in the Vicinity of the Borehole for Each Borehole Trajectory. The borehole inclination in radian is given as follows:

$$
i i_{i}:=10 \cdot i \cdot\left(\frac{\pi}{180}\right) .
$$

The borehole azimuth angle in radian is given as follows:

$$
\alpha_{k}:=10 \cdot k \cdot\left(\frac{\pi}{180}\right)
$$

The in situ stresses in the coordinate system $(x, y, z)$ are given as follows:

$$
\begin{aligned}
\sigma_{x_{i, k}:=} & \left(\sigma_{H} \cdot \cos \left(\alpha_{k}\right)^{2}+\sigma_{h} \cdot \sin \left(\alpha_{k}\right)^{2}\right) \cdot \cos \left(i i_{i}\right)^{2} \\
& +\sigma_{v} \cdot \sin \left(i i_{i}\right)^{2} \\
\sigma_{y_{k}:=} & \sigma_{H} \cdot \sin \left(\alpha_{k}\right)^{2}+\sigma_{h} \cdot \cos \left(\alpha_{k}\right)^{2}, \\
\sigma_{z z_{i, k}:=} & \left(\sigma_{H} \cdot \cos \left(\alpha_{k}\right)^{2}+\sigma_{h} \cdot \sin \left(\alpha_{k}\right)^{2}\right) \cdot \sin \left(i i_{i}\right)^{2} \\
& +\sigma_{v} \cdot \cos \left(i i_{i}\right)^{2}, \\
\sigma_{x y_{i, k}:=} & 0.5 \cdot\left(\sigma_{h}-\sigma_{H}\right) \cdot \sin \left(2 \cdot \alpha_{k}\right) \cdot \cos \left(i i_{i}\right), \\
\sigma_{x z_{i, k}:=} & 0.5 \cdot\left(\sigma_{H} \cdot \cos \left(\alpha_{k}\right)^{2}+\sigma_{h} \cdot \sin \left(\alpha_{k}\right)^{2}-\sigma_{v}\right) \\
& \cdot \sin \left(2 \cdot i i_{i}\right), \\
\sigma_{y z_{i, k}:=} & 0.5 \cdot\left(\sigma_{h}-\sigma_{H}\right) \cdot \sin \left(2 \cdot \alpha_{k}\right) \cdot \sin \left(i i_{i}\right) .
\end{aligned}
$$


Specifying the Location of the Maximum Stress Concentration. The orientation of the maximum and minimum tangential stresses is given as follows:

$$
\begin{aligned}
& \theta 1_{i, k} \\
& :=\mid \begin{array}{ll}
\frac{\pi}{4}, & \text { if } \sigma_{x_{i, k}}=\sigma_{y_{k}}, \\
\frac{1}{2} \cdot a \cdot \tan \left[2 \cdot \frac{\sigma_{x y_{i, k}}}{\sigma_{x_{i, k}}-\sigma_{y_{k}}}\right], & \text { otherwise, }
\end{array} \\
& \theta 2_{i, k}:=\theta 1_{i, k}+\frac{\pi}{2} .
\end{aligned}
$$

Identifying the angle that is associated with the maximum tangential stress, one has

$$
\begin{aligned}
\sigma_{\theta 1 d_{i, k}:=} & \sigma_{x_{i, k}}+\sigma_{y_{k}}-2 \cdot\left(\sigma_{x_{i, k}}-\sigma_{y_{k}}\right) \\
& \cdot \cos \left(2 \cdot \theta 1_{i, k}\right)-4 \cdot \sigma_{x y_{i, k}} \\
& \cdot \sin \left(2 \cdot \theta 1_{i, k}\right) \\
\sigma_{\theta 2 d_{i, k}:=} & \sigma_{x_{i, k}}+\sigma_{y_{k}}-2 \cdot\left(\sigma_{x_{i, k}}-\sigma_{y_{k}}\right) \\
& \cdot \cos \left(2 \cdot \theta 2_{i, k}\right)-4 \cdot \sigma_{x y_{i, k}}
\end{aligned}
$$

$$
\begin{aligned}
& P_{w \_M_{0} i_{i, k}}:=\mid \text { for } j \in 1 \cdot P_{0} \cdots 1 \cdot \sigma_{\min } \\
& P_{w_{j}} \longleftarrow \frac{j}{1} \\
& \sigma_{\theta \max _{j}} \longleftarrow \sigma_{\theta d \max _{i, k}}-P_{w_{j}} \\
& \sigma_{r_{j}} \longleftarrow P_{w_{j}} \\
& \sigma_{p 1_{j}} \longleftarrow \frac{1}{2} \cdot\left(\sigma_{\theta \max _{j}}+\sigma_{z \max _{i, k}}\right)+\sqrt{\left(\sigma_{\theta z \max _{i, k}}\right)^{2}+\frac{1}{4} \cdot\left(\sigma_{\theta \max _{j}}-\sigma_{z \max _{i, k}}\right)^{2}} \\
& \sigma_{p 2_{j}} \longleftarrow \frac{1}{2} \cdot\left(\sigma_{\theta \max _{j}}+\sigma_{z \max _{i, k}}\right)-\sqrt{\left(\sigma_{\theta z \max _{i, k}}\right)^{2}+\frac{1}{4} \cdot\left(\sigma_{\theta \max _{j}}-\sigma_{z \max _{i, k}}\right)^{2}} \\
& \sigma_{1_{j}} \longleftarrow \max \left(\sigma_{p 1_{j}}, \sigma_{p 2_{j}}, \sigma_{r_{j}}\right) \\
& \sigma_{3_{j}} \longleftarrow \min \left(\sigma_{p 1_{j}}, \sigma_{p 2_{j}}, \sigma_{r_{j}}\right)
\end{aligned}
$$

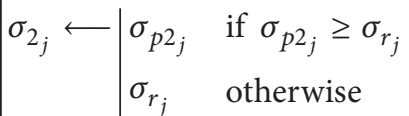

$$
\begin{aligned}
& \tau_{\text {oct }_{j}} \longleftarrow \frac{1}{3} \cdot\left[\sqrt{\left(\sigma_{1_{j}}-\sigma_{2_{j}}\right)^{2}+\left(\sigma_{2_{j}}-\sigma_{3_{j}}\right)^{2}+\left(\sigma_{3_{j}}-\sigma_{1_{j}}\right)^{2}}\right] \\
& \tau_{\operatorname{Mog}_{j}} \longleftarrow a+b \cdot\left[\frac{\left(\sigma_{1_{j}}+\sigma_{3_{j}}\right)}{2}-P_{0}\right] \\
& \text { break if } \tau_{\mathrm{Mog}_{j}}-\tau_{\mathrm{oct}_{j}} \geq 0 \\
& P_{w_{j}}
\end{aligned}
$$
lomb criterion:

$$
\theta \max _{i, k}:=\mid \begin{array}{ll}
\theta 1_{i, k}, & \text { if } \sigma_{\theta d \max _{i, k}}=\sigma_{\theta 1 d_{i, k}}, \\
\theta 2_{i, k}, & \text { otherwise. }
\end{array}
$$

The Axial and Shear Stresses in z-Plane at max. One has

$$
\begin{aligned}
& \sigma_{z \max _{i, k}}:=\sigma_{z z_{i, k}}-v \cdot\left[2 \cdot\left(\sigma_{x_{i, k}}-\sigma_{y_{k}}\right)\right. \\
& \left.\cdot \cos \left(2 \cdot \theta \max _{i, k}\right)+4 \cdot \sigma_{x y_{i, k}} \cdot \sin \left(2 \cdot \theta \max _{i, k}\right)\right], \\
& \sigma_{\theta z \max _{i, k}}:=2 \cdot\left(\sigma_{y z_{i, k}} \cdot \cos \left(\theta \max _{i, k}\right)-\sigma_{x z_{i, k}}\right. \\
& \left.\cdot \sin \left(\theta \max _{i, k}\right)\right) .
\end{aligned}
$$

follows:

$$
\sigma_{\theta d \max _{i, k}}:=\max \left(\sigma_{\theta 1 d_{i, k}}, \sigma_{\theta 2 d_{i, k}}\right) \text {. }
$$$$
\cdot \sin \left(2 \cdot \theta 2_{i, k}\right),
$$

Evaluation of the critical mud pressure using Mogi-Cou-

The location of the maximum stress concentration is given as 


\section{Competing Interests}

The authors declare that they have no competing interests.

\section{References}

[1] S. Khan, Wellbore stability during underbalanced drilling [M.S. thesis], 2006.

[2] M. McLean and M. Addis, "Wellbore stability analysis: a review of current methods of analysis and their field application," in Proceedings of the SPE/IADC Drilling Conference, Society of Petroleum Engineers, Houston, Tex, USA, 1990.

[3] J. P. Lowrey and S. Ottesen, "An assessment of the mechanical stability of wells offshore Nigeria," SPE Drilling \& Completion SPE-26351-PA, Society of Petroleum Engineers, 1995.

[4] A. M. Al-Ajmi and M. H. Al-Harthy, "Probabilistic wellbore collapse analysis," Journal of Petroleum Science and Engineering, vol. 74, no. 3-4, pp. 171-177, 2010.

[5] A. M. Al-Ajmi and R. W. Zimmerman, "Stability analysis of vertical boreholes using the Mogi-Coulomb failure criterion," International Journal of Rock Mechanics and Mining Sciences, vol. 43, no. 8, pp. 1200-1211, 2006.

[6] A. Al-Ajmi and R. W. Zimmerman, "Stability analysis of deviated boreholes using the mogi-coulomb failure criterion, with applications to some north sea and indonesian reservoirs," in Proceedings of the SPE Asia-Pacific Drilling Technology Conference, SPE 104035-MS, Bangkok, Thailand, November 2006.

[7] M. McLean and M. Addis, "Wellbore stability: the effect of strength criteria on mud weight recommendations," in Proceedings of the 65th SPE Annual Technical Conference and Exhibition, SPE 20405, New Orleans, La, USA, September 1990.

[8] B. S. Aadnoy, "Modeling of the stability of highly inclined boreholes in anisotropic rock formations," SPE Drilling Engineering, vol. 3, no. 3, pp. 259-268, 1988.

[9] E. Kårstad and B. S. Aadnoy, "Optimization of borehole stability using 3D stress optimization," in Proceedings of the SPE Annual Technical Conference and Exhibition, Dallas, Tex, USA, October 2005.

[10] E. Fjær, R. Holt, P. Horsrud, A. Raaen, and R. Risnes, Petroleum Related Rock Mechanics, Elsevier, Amsterdam, Netherlands, 2nd edition, 2008.

[11] A. M. Al-Ajmi and R. W. Zimmerman, "Relation between the Mogi and the Coulomb failure criteria," International Journal of Rock Mechanics and Mining Sciences, vol. 42, no. 3, pp. 431-439, 2005.

[12] A. Al-Ajmi, Wellbore stability analysis based on a new truetiaxial failure criterion [Ph.D. dissertation], Royal Institute of Technology, Stockholm, Sweden, 2006.

[13] S. K. Al-Shaaibi, A. M. Al-Ajmi, and Y. Al-Wahaibi, "Three dimensional modeling for predicting sand production," Journal of Petroleum Science and Engineering, vol. 109, pp. 348-363, 2011.

[14] Palisade, “@Risk software,” 2012, http://www.palisade.com. 


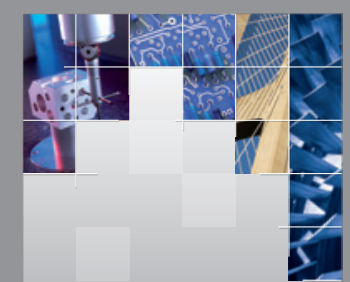

\section{Enfincering}
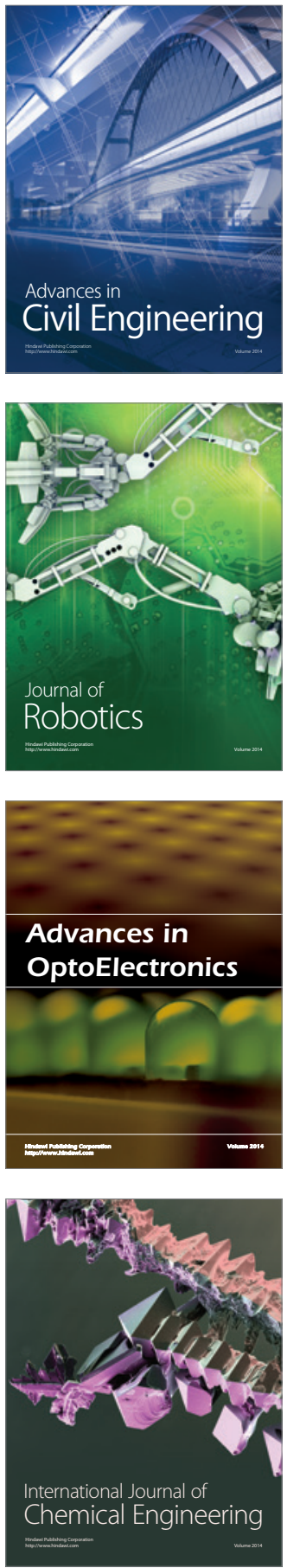

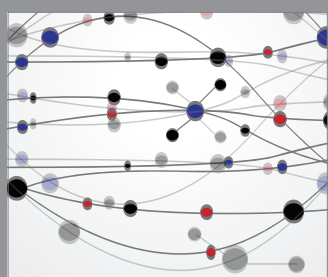

The Scientific World Journal

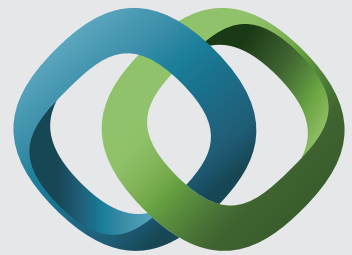

\section{Hindawi}

Submit your manuscripts at

http://www.hindawi.com
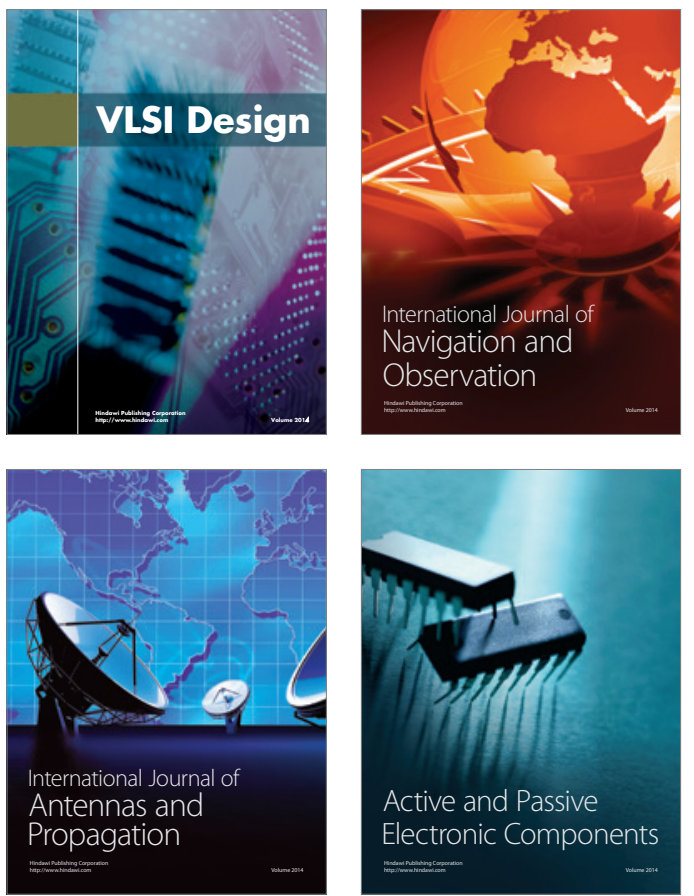
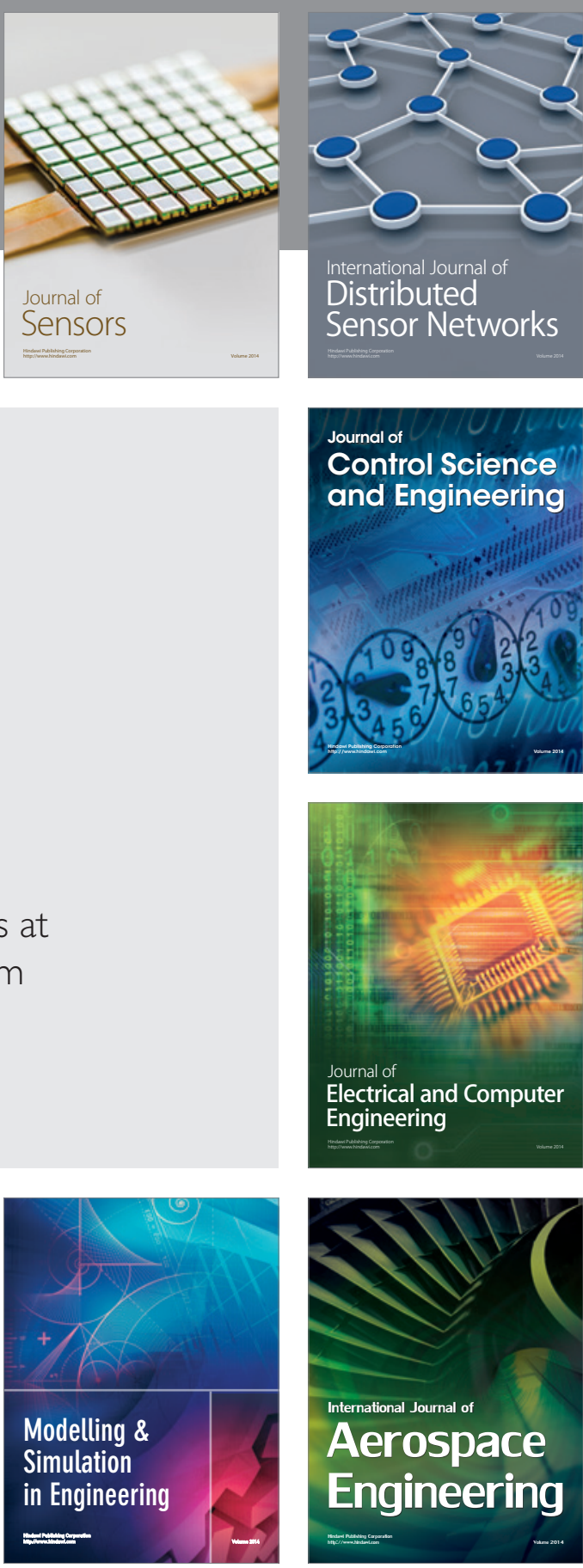

International Journal of

Distributed

Sensor Networks

Journal of

Control Science

and Engineering
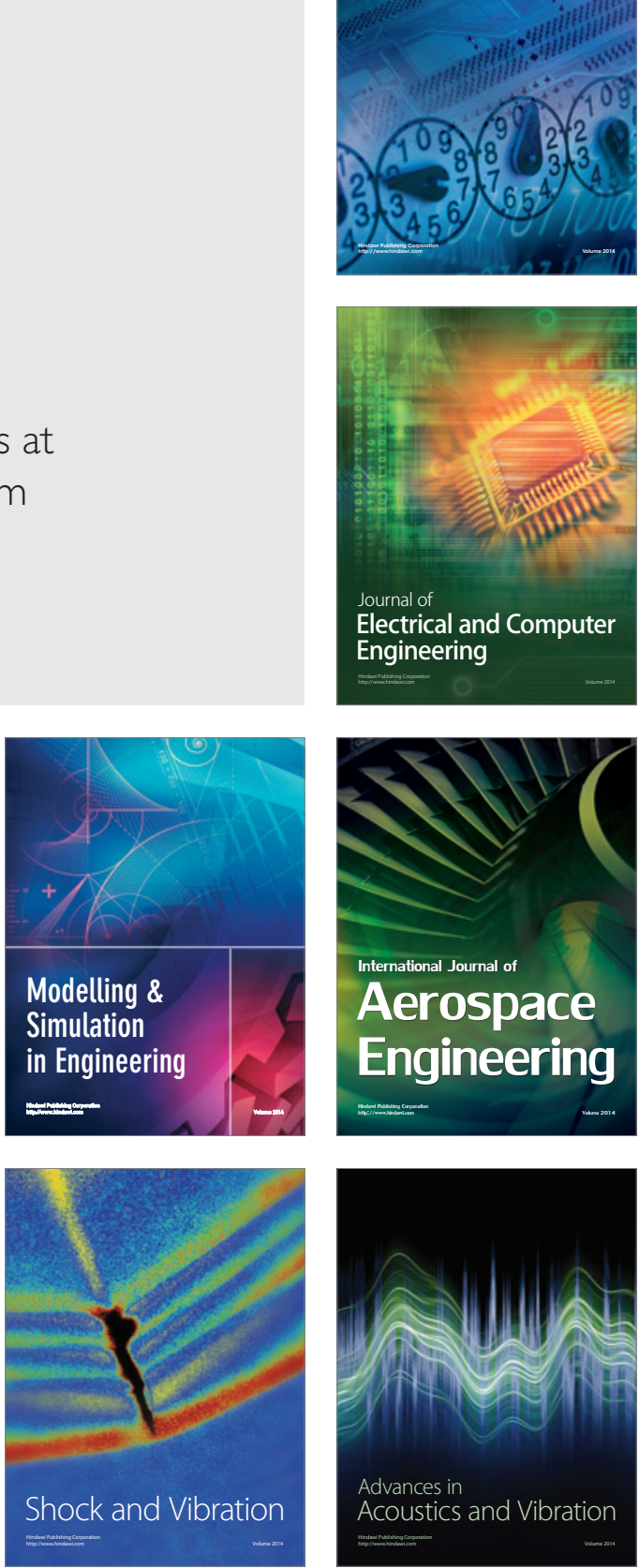